\title{
Announcement: In Memory of Bruno Eckhardt
}

It is with great sadness that we announce the unexpected passing of our dear colleague Bruno Eckhardt. Bruno was born March 25, 1960 and he died on August 7, 2019. He had served as Associate Editor for Physical Review E since 2007.

Bruno Eckhardt completed his Habilitation thesis at Philipps-Universität Marburg in Germany in 1992. Subsequently, he became a professor at Carl von Ossietzky Universität Oldenburg, and in 1996 he returned to Marburg as a professor of Physics. Throughout his career, he held a number of visiting positions including in Delft and Edinburgh.

A widely recognized leader in the areas of fluid dynamics, nonlinear dynamics, and chaos, Bruno made seminal contributions to understanding the transition to turbulence in pipe flow, nonlinear traveling waves in fluid flows, and quantum chaos. Bruno was awarded the Leibniz prize of the German science foundation, and he was recognized as a fellow of the American Physical Society, the Institute of Physics, and the European Mechanics Society.

Bruno had a distinguished editorial career. He served on the boards of Physical Review E, Nonlinearity, Journal of Nonlinear Science, and Physik Journal. As Associate Editor for Physical Review E he was responsible for the fluid dynamics section. During his tenure, this part of the journal has grown significantly. A skilled editor, Bruno was widely respected by his colleagues for his thoughtful comments and dedication. He was an effective spokesperson for the journal and a strong advocate for editorial excellence. Bruno, with his sharp intellect, excelled in just about any endeavor he took on.

Bruno will be remembered for his friendship, infectious smile, and keen sense of humor. We will deeply miss him.

We extend our condolences to Bruno's family and friends during this sad time.

\author{
Michael Thoennessen \\ Editor in Chief \\ American Physical Society \\ Eli Ben-Naim \\ Editor \\ Physical Review E \\ The Editors of Physical Review E
}

Published 27 August 2019

DOI: 10.1103/PhysRevE.100.020001 